\title{
Cultivo sem solo do morangueiro
}

\author{
Strawberry soilless cultivation
}

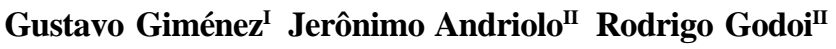

\section{- REVISÃO BIBLIOGRÁFICA -}

\section{RESUMO}

O morangueiro é uma cultura importante em vários países, principalmente nos Estados Unidos e na Europa, por suas características sensoriais, propriedades nutritivas e por sua rentabilidade. $O$ cultivo comercial sem solo de morangueiro está bem desenvolvido na Europa, onde tem permitido um aumento da produtividade e qualidade da produção assim como a ampliação da oferta do produto ao longo do ano. Predomina o sistema aberto, em sacolas ou vasos com diferentes tipos de substratos, utilizando-se densidades de 8 a 12plantas $\mathrm{m}^{-2}$. As produtividades obtidas estão entre $5 \mathrm{e} 10 \mathrm{~kg} \mathrm{~m}^{-2}$. Para isolar as plantas do solo e facilitar o manejo da cultura, os vasos ou sacolas são suspensos a uma altura entre 0,8 e $1 \mathrm{~m}$ da superfície do solo. A composição da solução nutritiva é variável, refletindo as diferentes condições produtivas. As mudas são produzidas principalmente em bandejas com substrato, a partir de pontas de estolões obtidas da multiplicação de plantas matrizes provenientes da propagação in vitro. No Brasil, o cultivo sem solo de morangueiro é ainda incipiente e os resultados produtivos e econômicos têm sido insatisfatórios, principalmente por falta de informações de pesquisas capazes de indicar sistemas apropriados de cultivo para as condições locais. É necessário desenvolver sistemas sustentáveis, preferencialmente fechados, combinando alta produtividade $e$ elevada eficiência de utilização da água e dos nutrientes. No presente trabalho, são revisados os principais aspectos da produção em sistemas de cultivo sem solo de mudas e fruta de morangueiro. São descritos a produção de mudas, os sistemas $e$ as soluções nutritivas empregadas em diferentes países. Ao final, são feitas inferências sobre a possibilidade de adoção $e$ geração do sistema de cultivo sem solo apropriado para as condições brasileiras.

Palavras-chave: Fragaria x ananassa, fertirrigação, substrato, hidroponia.

\section{ABSTRACT}

Strawberry is a very important crop in Europe and USA due to its nutritional and sensorial characteristics and its profitability. Nowadays, the traditional soil based crop production is being replaced by soilless growing systems, leading to higher yield and quality all over the year. Open systems with different kind of substrates in plastic bags or pots are mainly used, at plant densities from 8 to 12plants $\mathrm{m}^{-2}$. Fruit yield is in the range from 5 to $10 \mathrm{~kg} \mathrm{~m}^{-2}$. In general, plants are grown at 0.8-1m height above the soil surface, to isolate them from the soil and to facilitate the crop management. There are variations in the composition of the nutrient solution, reflecting differences in the conditions of crop production. Plug plants are produced in containers with substrate. They are obtained from runner tips of in vitro propagated mother plants. In Brazil, the strawberry soilless culture is in its first steps. Production and economical results are rather unsatisfactory, and researches about more appropriated cropping systems for local conditions are needed. Therefore, it is necessary to search for sustainable soilless growing systems, mainly of the closed type, to maximize yield under high water and nutrient use efficiency. Plant propagation, facilities and nutrient solutions used in different countries are described. Finally, guidelines for soilless crop systems appropriated for this crop in Brazilian conditions are presented.

Key words: Fragaria $x$ ananassa, fertigation, substrate, hydroponics.

\section{INTRODUÇÃO}

O interesse comercial pelo morangueiro é grande em muitos países. A coloração, o aroma e o sabor da fruta, assim como suas propriedades nutritivas, fazem do morango um produto muito apreciado pelos consumidores. O maior consumo ocorre in natura, mas pode ser processado em múltiplas formas, tais como em geléias, caldas, sucos e polpa congelada. É consumido também em laticínios, para a

IPrograma de Pós-graduação em Agronomia (PPGA), Universidade Federal de Santa Maria (UFSM), 97105-900, Santa Maria, RS, Brasil.

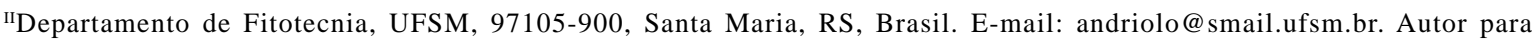
correspondência. 
produção de iogurtes e sorvetes, e na confeitaria, para elaboração de bolos, biscoitos e outros produtos (ALMEIDA et al., 1999). A fruta do morangueiro é rica em vitamina $\mathrm{C}$ e ácido fólico, possui elevado poder antioxidante, associado aos componentes fenólicos e pigmentos, e também uma elevada quantidade de ácido elágico, um constituinte com propriedades antimutagênicas e anticancerígenas. A medicina tem demonstrado que os componentes antioxidantes contidos nas frutas de morango possuem um efeito benéfico para a saúde, incluindo a diminuição da incidência de câncer, doenças cardíacas e retardamento no envelhecimento das funções cerebrais (MASS et al., 1991; TESTONI \& LOVATI, 1998; JOSEPH et al., 1998, 1999).

Os seis principais países em produção e produtividade de morango são, respectivamente, Estados Unidos (740.800t; 41 tha $\mathrm{t}^{-1}$ ), Espanha (306.000t; 38t ha ${ }^{-1}$ ), Japão (200.000t; 25t ha ${ }^{-1}$ ), Itália (172.600t; 23,5t $\left.h^{-1}\right)$, Coréia do Sul (151.200t; 20,5t ha-1) e Polônia (145.000t; 3t ha-1) (SANTOS \& MEDEIROS, 2003a). A produção brasileira alcançou um volume superior a 90 mil toneladas no ano de 1999. Os três principais Estados produtores são Minas Gerais, São Paulo e Rio Grande do Sul, os quais produzem $80 \%$ do morango brasileiro. A produtividade média da cultura no Brasil é de $25 t h^{-1}$, sendo quase a totalidade dessa produção proveniente do cultivo no solo (SANTOS \& MEDEIROS, 2003a). Essa produtividade situa-se abaixo daquela obtida em outros países, de até $70 \mathrm{t} \mathrm{ha}^{-1}$, mas é comparável àquela obtida em alguns dos principais países produtores (HENNION \& VESCHAMBRE, 1997; BARUZZI \& FAEDI, 1998; LIETEN, 1998; LIETEN et al., 2004).

O cultivo convencional do morangueiro no solo enfrenta problemas sanitários e ergonométricos. Os primeiros referem-se à contaminação dos solos por patógenos causadores de moléstias. A desinfecção do solo torna-se cada vez mais restritiva pelas dificuldades em substituir o brometo de metila por outros fumigantes com eficiência similar (LIETEN, 1998; PARANJPE et al., 2003). A questão ergonométrica evidencia-se pela elevada freqüência das colheitas rente ao solo, o que vem dificultando a disponibilidade de mão-de-obra para essa cultura. O cultivo sem solo em ambiente protegido sobre bancadas ou suportes acima do nível do solo é a alternativa apontada para superar esses entraves. Esse sistema permite ainda aumentar a densidade de plantas e a produtividade, diminuindo os custos da lavoura (LIETEN, 1993; 1998; MORAES \& FURLANI, 1999; PARANJPE et al., 2003).

O cultivo sem solo do morangueiro está bem difundido principalmente na Europa, onde teve início, em 1970, no sistema NFT (Nutrient Film Technique), a seja, técnica do fluxo laminar de nutrientes. Em seguida, passou por forte expansão na Inglaterra, Bélgica e Holanda, na década de 1980 (LIETEN, 1993). Atualmente, predominam os sistemas abertos, com drenagem perdida de solução nutritiva e plantas colocadas em sacolas ou vasos contendo diferentes tipos de substratos. Porém, a tendência é o cultivo com substratos em sistema fechado, com recirculação da solução nutritiva, por temas econômicos e ambientais. Esse sistema está ocupando uma área ao redor de 1.140ha (LIETEN et al., 2004). No Brasil, a cultura sem solo é ainda incipiente, devido principalmente à falta de informações de pesquisas que permitam a adaptação dos sistemas nas diferentes regiões produtivas do país (FURLANI \& FERNANDES JÚNIOR, 2004).

Essa revisão tem por objetivo descrever as principais características dos sistemas sem solo empregados na cultura do morangueiro em diferentes países, tanto para a produção de mudas como de frutas. Ao final, são feitas inferências sobre as características a serem buscadas na adaptação e/ou desenvolvimento de sistemas similares para as condições locais.

\section{Produção de mudas}

A produção de mudas de morangueiro pode ser realizada tanto em viveiros no campo quanto em cultivo sem solo, neste caso com emprego de solução nutritiva. O sistema de cultivo sem solo foi adotado rapidamente por viveiristas na Europa, nos Estados Unidos e no Canadá por permitir um melhor controle de fatores relacionados à sanidade, precocidade e produtividade (BISH et al., 1997; DURNER et al., 2002). Na Europa, as plantas matrizes provenientes da cultura de tecidos são plantadas em sacolas de plástico preenchidas com substrato. O solo sob as sacolas é coberto com filme de polietileno (mulching). As entrelinhas são cobertas com palha de trigo. As plantas matrizes emitem os estolões no final da primavera, quando se inicia a produção das mudas comerciais, preferencialmente em estufas ou túneis de polietileno (BISH et al., 1997; DURNER et al., 2002;). O principal método empregado para a produção das mudas comerciais consiste em extrair as pontas dos estolões, as quais são plantadas em bandejas contendo substrato. Mudas assim produzidas são denominadas de plug plants ou tray plants e adaptam-se ao sistema de produção de morangueiro em substrato. O emprego de substratos inertes evita a exposição das mudas a patógenos de solo (LIETEN, 1998; MUSACCHI \& MUSACCHI, 1998; DURNER et al., 2002; BISH \& CANTLIFFE, 2002). Vários autores têm observado que 
as mudas produzidas dessa forma são mais precoces, sendo úteis para produção de morango na entressafra, quando o valor do produto no mercado é mais elevado (LIETEN, 1998; DURNER, 1999; DURNER et al., 2002; BISH \& CANTLIFFE, 2002). Os materiais empregados como substratos para a produção de mudas em bandejas na Europa e nos Estados Unidos são diversos, como lã de rocha, vermiculita, perlita, turfa, areia, casca de pínus, poliestireno (BISH \& CANTLIFFE, 2002; DURNER et al., 2002).

No Brasil, existem recomendações para a produção de mudas comerciais de morangueiro em viveiros no campo (SANTOS \& MEDEIROS, 2003b; ANTUNES \& DUARTE FILHO, 2003) e cultivo sem solo (ANTUNES \& DUARTE FILHO, 2003). As plantas matrizes são produzidas in vitro, para assegurar a qualidade fisiológica e sanitária das mudas. Esse método vem sendo adotado no Brasil desde o final da década de 70. No sistema sem solo, a multiplicação das plantas matrizes é realizada em recipientes suspensos no interior de estufas de polietileno, com o emprego de substratos desinfestados por métodos químicos ou por solarização. Como substrato, é empregada, geralmente, a casca de arroz carbonizada. O fornecimento de nutrientes é realizado por fertirrigação (BETTI, 2000; FORTES, 2003).

Para o plantio em sistema NFT, é preferível utilizar mudas com raízes nuas, pois a eliminação do substrato aderido às raízes pode provocar danos mecânicos e estresse (PEREIRA \& MARTINEZ, 1999; MORAES \& FURLANI, 1999). Para esse sistema, a vermiculita ou perlita isoladas, a areia lavada e o algodão hidrófilo são alguns dos materiais indicados. Os mesmos autores mencionam ainda que os cubos de espuma fenólica e de lã de rocha também são apropriados para produzir mudas para sistemas hidropônicos do tipo NFT. MORAES \& FURLANI (1999) recomendam utilizar canais de cultivo de $0,05 \mathrm{~m}$ de profundidade e $0,10 \mathrm{~m}$ de diâmetro, com espaçamento de 0,10 a $0,15 \mathrm{~m}$ entre plantas, atingindo densidades de 45 a 100 plantas $\mathrm{m}^{-2}$. A solução nutritiva deve fluir a uma vazão de 1,5 a $2 \mathrm{~L}$ minn-1 $^{-1}$, com uma condutividade elétrica (CE) de 1,0 a 1,2dS m .

Produção de fruta

Dispositivos de cultura

A maior parte dos sistemas de cultivo sem solo para produção de fruta de morangueiro emprega algum tipo de substrato. Os substratos permitem melhor controle do teor de oxigênio e maior inércia térmica das raízes, quando comparados aos sistemas hidropônicos do tipo NFT (HENNION \& VESCHAMBRE, 1997; LIETEN, 1998). Podem ser empregados sacolas, vasos plásticos ou calhas contendo o substrato, que cumpre a função de suporte físico para as plantas, as quais são nutridas pela solução nutritiva.

Na Europa, o sistema mais comum emprega sacolas plásticas contendo de 8 a $10 \mathrm{dm}^{3}$ de substrato. São empregados como substratos turfa, perlita, lã de rocha ou fibra de coco, com três a quatro plantas por sacola, com densidades entre 8 e 12plantas $\mathrm{m}^{-2}$. Também, vêm sendo utilizados vasos de $2 \mathrm{dm}^{3}$ de volume, com os mesmos substratos. Tanto as sacolas como os vasos podem ser suspensos a diferentes alturas, isolando as plantas do solo e facilitando a colheita. São realizados plantios escalonados, os quais são combinados com manejos diferenciados do ambiente de forma a produzir o ano todo. Normalmente, são usadas as mesmas cultivares empregadas no cultivo no solo. Na Bélgica e Holanda, a principal cultivar é Elsanta (LIETEN, 1998). Na Itália, as cultivares “Marmolada”, “Miss”, “Elsanta”, “Tethis”, "Selene” e "Darselect” são as mais indicadas para o cultivo hidropônico (FAEDI et al., 1998). Na França, as cultivares recomendadas para este sistema são "Selva”, "Seascape”, "Darflash” e "Mara de Bois" (HENNION \& VESCHAMBRE, 1997). As produtividades são variáveis segundo a época, obtendo-se de 5 a $10 \mathrm{~kg} \mathrm{~m}^{-2}$ (HENNION \& VESCHAMBRE, 1997; BARUZZI \& FAEDI, 1998; LIETEN, 1998; LIETEN et al., 2004).

Nos Estados Unidos, o cultivo sem solo do morangueiro é recente, considerado até o momento uma alternativa viável somente no Estado da Flórida (PARANJPE et al., 2003). Diferentes recipientes, substratos, densidades de plantas e cultivares foram testados entre os anos de 2000 e 2002. Os melhores resultados foram obtidos com calhas de plástico corrugado em forma de $U$, suspensas a $1,50 \mathrm{~m}$ acima do solo e preenchidas com casca de pínus. A densidade de plantas de 22 plantas $\mathrm{m}^{-2}$ alcançou produtividade de 86t ha-1. As cultivares "Carmine", "Treasure", "Strawberry Festival” e "Camarosa” são as mais indicadas (PARANJPE et al., 2003).

No Brasil, o cultivo sem solo do morangueiro está em fase incipiente. MORAES \& FURLANI (1999) recomendam, para a produção em sistema NFT, canais de cultivo de $0,15 \mathrm{~m}$ de profundidade e $0,15 \mathrm{~m}$ de diâmetro, com um espaçamento entre plantas de 0,25 a $0,35 \mathrm{~m}$, com densidades de 8 a 16 plantas $\mathrm{m}^{-2}$. O comprimento dos canais não deve exceder a $15 \mathrm{~m}$, com uma declividade entre 0,02 e $0,04 \mathrm{~m} \mathrm{~m}^{-1}$. Aconselham empregar um volume de solução nutritiva entre 1,5 e 2L planta $^{-1}$ e uma vazão entre 2 e $4 \mathrm{~L} \mathrm{~min}{ }^{-1}$.

A produtividade das cultivares "Dover" e "Oso Grande” foram comparadas em dois sistemas hidropônicos do tipo NFT por BONECARRÈRE (2002). 
O primeiro foi constituído por telhas de fibrocimento de $3,7 \mathrm{~m}$ de comprimento e $1,10 \mathrm{~m}$ de largura com uma camada homogênea de brita basáltica de tamanho de partículas entre $0,015 \mathrm{~m}$ e $0,020 \mathrm{~m}$. O segundo foi composto por perfis de polipropileno de $3 \mathrm{~m}$ de comprimento e $5 \mathrm{~cm}$ de profundidade, sem qualquer substrato. As produtividades mais elevadas foram obtidas no perfil hidropônico, de $1,3 \mathrm{~kg} \mathrm{~m}^{-2}$, com a cultivar "Oso Grande" e no de $0,7 \mathrm{~kg} \mathrm{~m}^{-2}$ com a cultivar "Dover”, entre abril e setembro.

Em Santa Maria, ANDRIOLO et al. (2002) empregaram sacolas plásticas contendo $3,5 \mathrm{dm}^{3}$ do substrato orgânico Plantmax, fertirrigado semanalmente com uma solução nutritiva completa por meio de tubos gotejadores distribuídos sobre as sacolas, com um gotejador para cada planta. Obtiveram uma produtividade equivalente a $4 \mathrm{~kg} \mathrm{~m}^{-2}$, com a cultivar "Dover", entre abril e novembro.

Em sistema vertical, FURLANI \& FERNANDES JÚNIOR (2004) utilizaram, na região de Jundiaí, SP, sacolas longas de polietileno de cerca de $2 \mathrm{~m}$ de comprimento e $0,20 \mathrm{~m}$ de diâmetro, com volume de substrato em torno de 63L, penduradas no interior de uma estufa de polietileno. Os substratos testados no interior dessas sacolas foram: casca de arroz carbonizada, mistura de casca de pínus e vermiculita e mistura de fibra de coco, casca de arroz não-carbonizada e vermiculita ou fibra de coco. A distância entre sacolas foi de 1,2m, com espaçamento de $1 \mathrm{~m}$ entre fileiras. Em cada sacola, foram plantadas, em orifícios laterais, 28 plantas da cultivar "Campinas", distanciadas de 0,25m, atingindo uma densidade de 23plantas $\mathrm{m}^{-2}$. A casca de arroz carbonizada destacou-se pela baixa densidade aparente, baixo custo e produtividade de frutas de $8,7 \mathrm{~kg} \mathrm{~m}^{-2}$, entre os meses de setembro e dezembro. Entretanto, dificuldades na sustentação das sacolas, na uniformidade de distribuição da solução nutritiva na coluna de substrato e da radiação solar para as plantas são aspectos importantes a serem considerados neste sistema de cultivo.

No Estado do Rio Grande do Sul, o substrato mais empregado é a casca de arroz carbonizada, acondicionada em sacolas plásticas com aproximadamente $0,25 \mathrm{~m}$ de diâmetro e $1,0 \mathrm{~m}$ de comprimento, com três plantas. As sacolas são apoiadas em ripões individuais de madeira a uma altura de aproximadamente $1,0 \mathrm{~m}$ do solo, distanciados de $0,50 \mathrm{~m}$. Trata-se de um sistema aberto com drenagem perdida, onde a fertirrigação é efetuada através de tubos gotejadores. A casca de arroz carbonizada é empregada por ser de fácil disponibilidade e de baixo custo. Entretanto, seu emprego em larga escala apresenta dificuldades, relacionadas principalmente com o empirismo do processo de carbonização. Esse processo falha em obter um produto homogêneo e sofre restrições de natureza ambiental. Do ponto de vista da qualidade, a casca de arroz carbonizada é um material de baixa qualidade, com reduzida capacidade de retenção de água e pequena estabilidade, dificultando o manejo da fertirrigação (RODRIGUES, 2001).

Para o sistema NFT, VILLELA JÚNIOR et al. (2004), em Jaboticabal, SP, empregaram um dispositivo construído em bancadas, com 12,0m de comprimento, 2,0m de largura e 1,0m de altura. Os canais de cultivo foram constituídos por calhas de PVC com $0,10 \mathrm{~m}$ de diâmetro, com declividade entre 0,02 e $0,025 \mathrm{~m} \mathrm{~m}^{-2}$. A distância entre plantas foi de $0,30 \mathrm{~m}$, atingindo uma densidade de 10plantas $\mathrm{m}^{-2}$. O plantio foi feito em orifícios de $0,05 \mathrm{~m}$ de diâmetro, com a cultivar "Sweet Charlie”. Na época de outono-inverno, esses autores obtiveram uma produtividade de frutas de apenas $1 \mathrm{~kg} \mathrm{~m}^{-2}$, atribuída a níveis elevados da temperatura da solução nutritiva nesse sistema de cultivo.

Os turnos de irrigação no sistema NFT são variáveis, dependendo do estádio de desenvolvimento da cultura e das temperaturas do ar e da solução nutritiva. MORAES \& FURLANI (1999) recomendam turnos intermitentes de $10 \mathrm{~min}$, em climas amenos com temperaturas médias de $26^{\circ} \mathrm{C}$. Por sua vez, VILLELA JÚNIOR et al. (2004), na região de Jaboticabal, SP, utilizaram turnos de irrigação de $15 \mathrm{~min}$ e intervalos de 30min, aumentando para turnos intermitentes de 15min nas horas mais quentes do dia. BONECARRÈRE (2002), em Santa Maria, RS, utilizou turnos de 15min e intervalos de 30min.

\section{Composição da solução nutritiva}

São escassas na literatura as informações sobre o efeito da concentração dos nutrientes minerais sobre o crescimento, desenvolvimento e produtividade da cultura do morangueiro. São disponíveis alguns resultados de pesquisas indicando que a deficiência de $\mathrm{N}$ reduz simultaneamente o número, o tamanho e, conseqüentemente, a produtividade (DENG \& WOODWARD, 1998). Na fase de estolonamento, afeta tanto o comprimento como o número de ramificações dos estolões. O número de ramificações aumenta enquanto o comprimento dos estolões diminui sob níveis elevados de N (TWORKOSKI et al., 2001). Níveis moderados após o plantio até meados de outono, quando as temperaturas são ainda elevadas e o fotoperíodo longo, favorecem o aumento no número de rebentos da coroa. Por outro lado, níveis elevados no final do outono reduzem a produtividade e a qualidade dos frutas na primavera seguinte, favorecendo a emissão precoce de estolões (HENNION \& VESCHAMBRE, 1997).

Diversas formulações de soluções nutritivas para o cultivo sem solo do morangueiro foram descritas na literatura (tabela 1 ). Com relação aos macronutrientes, as concentrações máximas e mínimas nas diferentes soluções formuladas foram de 4 e $12 \mathrm{mmol}$ 
Tabela 1 - Concentração de macronutrientes em soluções nutritivas para o cultivo sem solo do morangueiro.

\begin{tabular}{|c|c|c|c|c|c|c|c|}
\hline \multirow{2}{*}{ Autor } & \multicolumn{7}{|c|}{ Concentração (mmol L') } \\
\hline & $\mathrm{NO}_{3}^{-}$ & $\mathrm{NH}_{4}^{-}$ & $\mathrm{K}^{+}$ & $\mathrm{H}_{2} \mathrm{PO}_{4}$ & $\mathrm{Ca}^{++}$ & $\mathrm{Mg}^{++}$ & $\mathrm{SO}_{4}^{--}$ \\
\hline SAZAKI (1992) & 5,2 & 0,6 & 2,8 & 0,4 & 1,1 & 0,5 & 0,5 \\
\hline SONNEVELD \& STRAVER (1994) & 10 & 0,5 & 5,2 & 1,2 & 2,7 & 1,1 & 1,1 \\
\hline MUCKLE (1993) & 7,2 & 0,2 & 5,3 & 1,4 & 3,1 & 2,0 & 4,2 \\
\hline CASTELLANE \& ARAÚJO (1994) & 8,9 & ---- & 4,5 & 1,5 & 3,0 & 1,0 & 1,0 \\
\hline MORAES \& FURLANI (1999) & 10,2 & 2,0 & 6,4 & 2,0 & 3,8 & 1,6 & 1,6 \\
\hline FURLANI \& FERNANDES JÚNIOR (2004) ${ }^{1}$ & 8,3 & 0,8 & 3,8 & 1,6 & 2,6 & 1,5 & 1,5 \\
\hline FURLANI \& FERNANDES JÚNIOR $(2004)^{2}$ & 8,3 & --- & 4,6 & 1,6 & 2,6 & 1,5 & 1,5 \\
\hline SAROOSHI \& CRESSWELL (1994) & 9,8 & 2,5 & 7,5 & 1,2 & 2,4 & 1,2 & ---- \\
\hline HENNION \& VESCHAMBRE ${ }^{1}$ (1997) & 12,0 & 2,0 & 6,0 & 2,2 & 3,0 & 1,25 & 1,0 \\
\hline HENNION \& VESCHAMBRE ${ }^{2}$ (1997) & 10,0 & ---- & 6,5 & 2,0 & 3,25 & 1,0 & 1,0 \\
\hline PARANJPE et al. (2003) & 4,0 & 0,7 & 2,2 & 1,6 & 2,4 & 1,6 & 1,7 \\
\hline
\end{tabular}

${ }^{1}$ Fase vegetativa; ${ }^{2}$ fase de frutificação.

$\mathrm{L}^{-1}$ para oNO ${ }_{3}^{-} ; 0,2 \mathrm{e} 2,5 \mathrm{mmol} \mathrm{L}^{-1}$ para o $\mathrm{NH}_{4}^{+} ; 2,2 \mathrm{e} 7,5 \mathrm{mmol}$ $\mathrm{L}^{-1}$ para o K $; 0,4 \mathrm{e} 2,2 \mathrm{mmol} \mathrm{L}^{-1}$ para o $\mathrm{H}_{2} \mathrm{PO}_{4} ; 1,1 \mathrm{e} 3,8 \mathrm{mmol}$ $\mathrm{L}^{-1}$ para o $\mathrm{Ca}^{++} ; 0,5 \mathrm{e} 2,0 \mathrm{mmolL}^{-1}$ para o $\mathrm{Mg}^{++}$e $0,5 \mathrm{e} 4,2 \mathrm{mmol}$ $\mathrm{L}^{-1}$ para o $\mathrm{SO}_{4}^{--}$. Com relação aos micronutrientes, as concentrações que aparecem nas soluções dos mesmos autores, em mg L ${ }^{-1}$, variam entre 0,2 e 0,5 para o B; 0,01 e0,05 para o Cu; 1,0 e 3,0 para o Fe; 0,2 e 0,6 para o Mn; 0,005 e 0,05 para o Mo e entre 0,02 e 0,3 para o Zn. Fatores como concentração, equilíbrio eletroquímico, teor de oxigênio, temperatura do ar e da solução nutritiva e intensidade da radiação solar incidente modificam as dinâmicas de absorção mineral e estão na origem das variações na composição das soluções descritas na literatura. Isso significa que a composição da solução nutritiva deve ser ajustada para as diferentes condições de produção.

Em relação ao $\mathrm{pH}$ e à $\mathrm{CE}$ elétrica das soluções nutritivas, os valores variam segundo a composição química. Vários autores enfatizam que a cultura de morangueiro é muito sensível à salinidade, a qual poderia provocar reduções de produtividade. Por outro lado, valores de $\mathrm{CE}$ muito baixos podem diminuir a qualidade da fruta. As faixas entre 5,5 e 6,5 para o $\mathrm{pH}$ e entre 1,4 e 1,8 dS m ${ }^{-1}$ para a CE são indicadas como aquelas mais favoráveis à produtividade e qualidade das frutas (LIETEN, 1993, 1998; SAROOSHI \& CRESSWELL, 1994; PARANJPE et al., 2003; FURLANI \& FERNANDEZ JÚNIOR, 2004).

Uma das formas de monitorar a eficiência de absorção dos nutrientes consiste em diagnosticar o estado nutricional da planta mediante os teores existentes nos tecidos. A folha é o órgão a ser analisado e os teores críticos para a planta do morangueiro estão descritos na tabela 2 .

A fertirrigação descontínua é uma prática que pode ser empregada em cultivos que empregam substratos dotados de CTC (capacidade de troca catiônica). Nesse caso, os cátions nutrientes sofrem menos lixiviação em relação aos substratos inertes e uma parte desses nutrientes pode ser aplicada ao substrato antes de iniciar o cultivo. Para efetuar o ajuste da adubação de acordo com a demanda da cultura nessa modalidade de cultivo em substrato, deve-se conhecer as quantidades de nutrientes extraídas no decorrer do ciclo de crescimento e desenvolvimento da cultura, a fim de atingir-se o potencial de produtividade da cultura. As quantidades extraídas por algumas cultivares estão descritas na tabela 3.

Tabela 2 - Teores críticos de nutrientes na matéria seca de folhas de plantas de morangueiro.

\begin{tabular}{|c|c|c|}
\hline Nutriente & ULRICH et al. (1992) & HENNION \& VESCHAMBRE (1997) \\
\hline $\mathrm{N}-\mathrm{NO}_{3}{ }^{-}$ & 0,5 $\mathrm{g} \mathrm{kg}^{-1}$ - Pecíolo & $0,5 \mathrm{~g} \mathrm{~kg}^{-1}-$ Limbo \\
\hline N-Total & $28 \mathrm{gg}^{-1}$ - Limbo & -- \\
\hline $\mathrm{K}^{+}$ & $10 \mathrm{gg}^{-1}$ - Limbo & $21-25 \mathrm{~g} \mathrm{~kg}^{-1}-$ Limbo \\
\hline $\mathrm{P}-\mathrm{H}_{2} \mathrm{PO}_{4}^{-}$ & 0,7g kg ${ }^{-1}$ - Pecíolo & $4 \mathrm{~g} \mathrm{~kg}^{-1}-$ Limbo \\
\hline P-Total & $1 \mathrm{~g} \mathrm{~kg}^{-1}$ - Limbo & -- \\
\hline $\mathrm{Mg}^{++}$ & $2 \mathrm{~g} \mathrm{~kg}^{-1}$ - Limbo & 2,4 - 2,8g kg-1 - Limbo \\
\hline $\mathrm{Ca}^{++}$ & $3 g \mathrm{~kg}^{-1}-$ Limbo & $6-11 \mathrm{~g} \mathrm{~kg}^{-1}-$ Limbo \\
\hline $\mathrm{S}-\mathrm{SO}_{4}^{--}$ & $0,1 \mathrm{~g} \mathrm{~kg}^{-1}-$ Limbo & -- \\
\hline
\end{tabular}

Ciência Rural, v.38, n.1, jan-fev, 2008. 
Tabela 3 - Quantidades totais de nutrientes (g planta ${ }^{-1}$ ) extraídas pela planta do morangueiro ao final do ciclo de crescimento e desenvolvimento da cultura.

\begin{tabular}{|c|c|c|c|c|c|c|c|}
\hline Autor & Cultivar & $\mathrm{N}$ & $\mathrm{P}$ & K & $\mathrm{Ca}$ & $\mathrm{Mg}$ & $\mathrm{S}$ \\
\hline SOUZA et al. (1976) & "Monte Alegre" & 1,33 & 0,23 & 1,36 & 0,73 & 0,25 & 0,20 \\
\hline SOUZA et al. (1976) & “Campinas” & 1,61 & 0,36 & 1,87 & 0,73 & 0,30 & 0,21 \\
\hline HENNION \& VESCHAMBRE (1997) & "Gariguette" & 3,0 & 0,80 & 3,66 & 1,25 & 0,54 & --- \\
\hline LIETEN \& MISOTTEN (1993) & “Elsanta” & 1,56 & 0,5 & 2,37 & 0,975 & 0,29 & ---- \\
\hline
\end{tabular}

Em ordem decrescente de extração aparecem K, N, Ca, P, Mg e S. FURLANI et al. (1999) sugerem formular soluções nutritivas observando as seguintes proporções em relação ao K: 0,67; 0,10; 0,67; 0,27 e 0,10 para N, P, Ca, Mg e S, respectivamente. Entretanto, a absorção dos nutrientes varia com as fases fenológicas durante o ciclo de desenvolvimento da cultura, existindo indicações de que as concentrações dos elementos devem ser diferentes para cada uma dessas fases (LIETEN \& MISOTTEN, 1993; TAGLIAVINNI et al., 2005).

O cultivo sem solo é a mudança de escala tecnológica necessária para eliminar a prática da desinfecção do solo tanto na fase de produção de mudas como de fruta na cultura do morangueiro. Os sistemas a serem desenvolvidos devem ser do tipo fechado, com emprego de substratos. Os substratos devem combinar elevada aeração e capacidade de retenção de água, de forma a reduzir a freqüência das fertirrigações e os riscos do estresse hídrico no decorrer do ciclo da cultura. Devem também ser capazes de aumentar a inércia térmica da solução nutritiva, especialmente nos períodos quentes do ano. Os materiais a serem empregados como substratos devem ter disponibilidade e custo acessíveis em cada região de produção. A composição da solução nutritiva deve ser ajustada de acordo com as variáveis meteorológicas de cada região de produção, para combinar produtividade e qualidade de fruta. A seleção de cultivares adaptadas ao cultivo sem solo deve ser incluída como um dos objetivos do melhoramento genético dessa cultura. O descarte mínimo da solução nutritiva pode ser buscado mediante o ajuste periódico da sua composição, de forma a minimizar ou evitar a substituição ao longo do ciclo de crescimento e desenvolvimento.

\section{CONCLUSÕES}

A maior parte dos sistemas sem solo atualmente empregados no mundo para o cultivo do morangueiro emprega substratos e são abertos. No Brasil, ainda não existe um sistema claramente definido para o cultivo sem solo dessa cultura, o qual é uma tendência para os próximos anos. Os sistemas a serem desenvolvidos devem combinar alta produtividade e qualidade de fruta, baixo custo e reduzido impacto ambiental.

\section{REFERÊNCIAS}

ALMEIDA, M.E.M. et al. A industrialização do morango. Informe Agropecuário, v.20, n.198, p.84-88, 1999.

ANDRIOLO, J.L. et al. Acumulação de matéria seca e rendimento de frutas de morangueiro cultivado em substrato com diferentes soluções nutritivas. Horticultura Brasileira, v.20, n.1, p.24-27, 2002.

ANTUNES, L.E.C.; DUARTE FILHO, J. Produção de mudas de morango. In: SANTOS, A.M. dos; MEDEIROS, A.R.M (Eds). Sistema de produção do morango. Sistemas de produção, 5. Pelotas: EMBRAPA CT, 2003. Acesso em: 24 mar. 2006. Online. Disponível na Internet: http;//www.cpact.embrapa/ sistemna/morango.

BARUZZI, G; FAEDI, W. La fragola in Italia. In: FAEDI, W. (Ed.). La Fragola verso il 2000. Convegno Nazionale. Verona: Camera di Commercio Industria Artigianato e Agricultura, 1998. p.95-110.

BETTI, J.A. Matrizes básicas IAC de Morangueiro. O Agronômico, v.52, n.1, p.28-29, 2000.

BISH, E.B.; CANTLIFFE, D.J. Temperature conditioning and container size affect early season fruit yield of strawberry plug plants in a winter, annual hill production system. HortScience, v.37, n.5, p.762-764, 2002.

BISH, E.B. et al. Development of containerized strawberry transplants for Florida's winter production system. Acta Horticulturae, v.439, p.461-468, 1997.

BONNECARRÈRE, R.A.G. Soluções nutritivas e formas de manejo do morangueiro em hidroponia. 2002. $88 \mathrm{f}$. Dissertação (Mestrado em Agronomia) - Curso de Pós-graduação em Fitotecnia, Universidade Federal de Santa Maria.

CASTELLANE, P.D.; ARAUJO, J.A.C.de. Cultivo sem solo: hidroponia. Jaboticabal: FUNEP, 1994. 43p.

DENG, X.; WOODWARD, F.I. The growth and yield responses of Fragaria ananassa to elevated $\mathrm{CO}_{2}$ and N Supply. Annals of Botany, v.81, p.67-71, 1998. 
DURNER, E.F. Winter greenhouse strawberry production using conditioned plug plants. HortScience, v.34, n.4, p.615-616, 1999.

DURNER, E.F. et al. Recent advances in strawberry plug transplant technology. HortTechnology, v.12, n.4, p.545550, 2002.

FAEDI, W. et al. Il miglioramento genético e le varietà di fragola. In: FAEDI, W. (Ed.). La Fragola verso il 2000. Convegno Nazionale. Verona: Camera di Commercio Industria Artigianato e Agricultura, 1998. p.95-110.

FORTES, G.R.L. Produção de mudas básicas. In: SANTOS, A.M.; MEDEIROS, A.R.M. (eds). Morango. Produção. Frutas do Brasil, 40. Brasília: EMBRAPA CT, 2003. p.31-34.

FURLANI, P.R. et al. Nutrição mineral de hortaliças, preparo e manejo de soluções nutritivas. Informe Agropecuário, v.20, n.200/201, p.90-98, 1999.

FURLANI, P.R.; FERNANDEZ JÚNIOR, F. Cultivo hidropônico de morango em ambiente protegido. In: SIMPÓSIO NACIONAL DO MORANGO \& ENCONTRO DE PEQUENAS FRUTAS E FRUTAS NATIVAS DO MERCOSUL, 2., 2004, Pelotas. Anais.. Pelotas: Corrêa Antunez, L.E. et al., (eds.). EMBRAPA, 2004 p.102-115. (Documentos 124).

HENNION, B.; VESCHAMBRE, D. La fraise: maîtrise de la production. Paris: CTIFL, 1997. 299 p.

JOSEPH, J.A. et al. Long-term dietary strawberry, spinach, or vitamin E supplementation retards the onset of age-related neuronal signal-transduction and cognitive behavioral deficits. Journal of Neuroscience. v.18, n.19, p.8047-8055, 1998.

JOSEPH, J.A. et al. Reversals of age-related declines in neuronal signal transduction, cognitive, and motor behavioral deficits with blueberry, spinach, or strawberry dietary supplementation. Journal of Neuroscience, v.19, n.18, p.8114-8121, 1999.

LIETEN, F. Methods and strategies of strawberry forcing in Europe. Historical perspectives and recent developments. Acta Horticulturae, v.348, p.158-170, 1993.

LIETEN, F. La fragola in Belgio-Olanda. In: FAEDI, W. (ed.) La Fragola verso il 2000. Convegno Nazionale. Verona: Camera di Commercio Industria Artigianato e Agricultura, 1998. p.83-94.

LIETEN, F.; MISOTTEN, C. Nutrient uptake of strawberry plants (cv. Elsanta) grown in substrate. Acta Horticulturae, v.348, p.299-306, 1993.

LIETEN, F. et al. Recent situation of strawberry substrate culture in Europe. Acta Horticulturae, v.649, p.193-196, 2004

MAAS, J.L. et al. Evaluation of strawberry genotypes for ellagic acid, an antimutagenic and anticarcinogenic plant phenol. In: DALE, A., LUBY, J. (Eds.). The strawberry into the $21^{\text {st }}$ Century. Oregon, Portland: Timber, 1991. p.115-117.

MORAES, C.A.G.; FURLANI, P.R. Cultivo de hortaliças de fruta em hidroponia. Informe Agropecuário, v.20, n.200/ 201, p.105-113, 1999.

MUCKLE, M.E. Hydroponic nutrients. Princeton: Growers, 1993. 154p.
MUSACCHI, S.; MUSACCHI, D. Aggiornamenti della tecnica colturale della fragola nelle aree meridionali. In: FAEDI, W. (Ed.). La Fragola verso il 2000. Convegno Nazionale. Verona: Camera di Commercio Industria Artigianato e Agricultura, 1998. p.167-177.

PARANJPE A. et al. Winter strawberry production in greenhouses using soilless substrates: an alternative to methyl bromide soil fumigation. Proceedings of the Florida State for Horticultural Science, Florida, v.116, p.98-105, 2003.

PEREIRA, P.R.G.; MARTINEZ, H.E.P. Produção de mudas para o cultivo de hortaliças em solo e hidroponia. Informe Agropecuário, v.20, n.200/201, p.24-31, 1999.

RODRIGUES, L.T. Caracterização e resposta agronômica de substratos na produção de mudas de fumo no sistema float. 2001. 66f. Dissertação (Mestrado em Ciências) - Curso de Pós-graduação em Agronomia, Universidade Federal de Pelotas.

SANTOS, A.M.; MEDEIROS, A.R.M. (Eds). Morango. Produção. Frutas do Brasil, 40. Brasília: EMBRAPA CT, 2003a. 81p.

SANTOS, A.M.; MEDEIROS, A.R.M. Produção de mudas comerciais de morango. In: SANTOS, A.M.; MEDEIROS, A.R.M. (eds). Morango. Produção. Frutas do Brasil, 40. Brasília: EMBRAPA CT, 2003b. p.35-38.

SAROOSHI, R.A.; CRESSWELL, G.C. Effects of hydroponic solution composition, electrical conductivity and plant spacing on yield and quality of strawberries. Australian Journal of Experimental Agriculture, v.34, p.529-535, 1994.

SAZAKI, J.L.S. Hidroponia. In: SEMANA DA AGRONOMIA 9, 1992, Ilha Solteira. Palestras... Ilha Solteira: UNESP-Ilha Solteira, 1992. 9p.

SONNEVELD, C; STRAVER, $N$. Nutrient solutions for vegetables and flowers grown in water or substrates. The Netherlands: Proefstation voor Tuinbouw onder Glas Te Naaldwijk, 1994. 45p.

SOUZA, A.F. et al. Nutrição mineral de hortaliças. XXIX absorção de micronutrientes por quatro cultivares de morangueiro (Fragaria spp.). Anais da Escola Superior Superior de Agricultura “Luiz de Queiroz”, v.33, p.647683, 1976

TAGLIAVINI, M. et al. Dynamics of nutrients uptake by strawberry plants (Fragaria $x$ ananassa Dutch.) grown in soil and soilless culture. European Journal of Agronomy, v.23, n.1, p.15-25, 2005.

TESTONI, A.; LOVATI, F. Considerazioni su alcuni aspetti qualitativi dei fruti di fragola. In: FAEDI, W. (Ed.). La Fragola verso il 2000. Convegno Nazionale. Verona: Camera di Commercio Industria Artigianato e Agricultura, 1998. p.263277.

TWORKOSKI, T.J. et al. The effect of nitrogen on stolon and ramet growth in four genotypes of Fragaria chiloensis L. Scientia Horticulturae, v.88, p.97-106, 2001.

ULRICH, A. et al. Strawberry deficiency symptoms: a visual and plant analysis guide to fertilization. Oakland: University of Califórnia. 1992. 58p. (Bulletin 1917).

VILLELA JÚNIOR L.V.E. et al. Análise do resfriamento da solução nutritiva para cultivo hidropônico do morangueiro. Engenharia Agrícola, v.24, n.2, p.338-346, 2004. 